\title{
ANALISIS MODEL BISNIS PADA KNM FISH FARM DENGAN PENDEKATAN BUSINESS MODEL CANVAS (BMC) \\ Business Model Analysis of KNM Fish Farm with Business Model Canvas (BMC) Approach
}

\author{
"Eius Solihah"1, Aida Vitayala S. Hubeis ${ }^{2}$ dan Agus Maulana ${ }^{2}$ \\ ${ }^{1}$ Program Pascasarjana dan Bisnis - IPB \\ ${ }^{2}$ Pusat Pelatihan Kelautan dan Perikanan - BPSDM KP \\ "email: euis_solihah.puslatkp@yahoo.com \\ Diterima 25 Juli 2013 - Disetujui 3 Nopember 2014
}

\begin{abstract}
ABSTRAK
Usaha di bidang perikanan menghadapi berbagai kendala, sehingga untuk menjaga keberlangsungan usahanya, menuntut KNM Fish Farm yang merupakan usaha keluarga yang bergerak di bidang budidaya perikanan air tawar agar meningkatkan kinerja dengan cara memperbaiki model bisnis yang selama ini digunakan dalam menjalankan bisnisnya. Tujuan dari penelitian ini adalah: (1) Mengidentifikasi model bisnis di KNM Fish Farm menggunakan BMC, (2) Menciptakan model bisnis perbaikan pada KNM Fish Farm. Data dikumpulkan dari Desember 2013 hingga Februari 2014 dan menggunakan metode deskriptif dengan pendekatan studi kasus pada KNM Fish Farm. Alat analisis yang digunakan yaitu Business Model Canvas (BMC) dan Analisis SWOT. Penelitian ini difokuskan untuk membuat model bisnis baru dengan pendekatan Business Model Canvas (BMC) yang melihat perusahaan melalui sembilan elemen, yaitu: (1) Customer segmentations, (2) Value Propositions, (3) Channels, (4) Customer relationship, (5) Revenue streams, (6) Key Resources, (7) Key Activities, (8) Key Partnerships, dan (9) Cost Structure. Hasil penelitian ini menunjukkan bahwa model bisnis yang selama ini dilakukan oleh KNM Fish Farm ditemukan kelemahan pada ke-9 elemen BMC, oleh karena itu perlu dilakukan perbaikan pada semua elemen.
\end{abstract}

Kata Kunci: Business Model Canvas (BMC), model bisnis, usaha keluarga, budidaya ikan air tawar

\begin{abstract}
Business in the field of fisheries face numerous obstacles, so as to maintain business continuity, demanding KNM Fish Farm which is a family business which is engaged in the cultivation of freshwater fisheries, in order to improve performance by improving the business model that had been used in the conduct of its business. The purpose of this study are: (1) Identify the business model in KNM Fish Farm using BMC, (2) Creating a business model improvements on KNM Fish Farm. Data were collected from December 2013 to February 2014, and using methods of descriptive case study approach on KNM Fish Farm. Analysis tool that is used in the Business Model Canvas (BMC) and SWOT analysis. This study is focused to create a business model with Business Model Canvas approach which saw the company through nine elements : (1) Customer segmentations, (2) Value propositions, (3) Channels, (4) Customer relationship, (5) Revenue streams, (6) Key Resources, (7) Key Activities, (8) Key Partnerships, and (9) Cost Structure. Results of this study indicate that the business model that has been done by KNM Fish Farm was found weaknesses in the $9^{\text {th }}$ element of the BMC, therefore need to be repaired at all elements.
\end{abstract}

Keywords: Business Model Canvas (BMC), business model, cultivation of freshwater, family business 


\section{PENDAHULUAN}

Keluarga Nurjen Muchtar (KNM) Fish Farm adalah usaha keluarga yang bergerak di bidang pembenihan, budidaya ikan mas dan nila yang sudah berjalan sejak tahun 1953 dan akan memasuki generasi ketiga. Harapan ke depan usaha di bidang perikanan ini dapat terus berkembang dan diturunkan ke generasi-generasi selanjutnya. Pada tahun 1984 usaha keluarga ini diteruskan oleh generasi kedua dan jenis ikan yang dikelola bertambah dengan jenis ikan hias seperti ikan koi, komet, baster, dan lain-lain. Sejak tahun 2007 usaha yang dijalankan KNM Fish Farm terus mengalami berbagai permasalahan.

Permasalahan yang dihadapi berupa tingginya harga pakan pabrik (pellet) dan pupuk yang merupakan biaya operasional terbesar mencapai $70 \%$. Biaya operasional yang besar ini tidak tertutupi oleh harga jual ikan yang relatif rendah di tingkat pembudidaya yang dipatok oleh pedagang pengumpul/tengkulak. KNM Fish Farm juga memiliki berbagai sumber daya yang selama ini belum dimanfaatkan secara optimal seperti lahan yang cukup luas dan SDM terdidik yang berasal dari generasi ketiga.
Menurut Sa'id (2010) beberapa sifat yang harus dimiliki oleh seorang wirausaha yang bergerak dalam bidang agribisnis diantaranya mampu bekerja secara terencana atau terorganisasi dengan baik dan mampu meneropong peluang bisnis yang besar dan memiliki kemampuan melakukan tinjauan bisnis ke masa depan dengan menerapkan cara kerja yang efisien, berani mengambil resiko, kreativitas dan inovasi serta kemampuan manajemen untuk mencari dan membaca peluang. Melihat prospek usaha perikanan ke depan yang cukup menjanjikan dan tingginya persaingan serta berbagai permasalahan yang dihadapi, maka KNM Fish Farm perlu memperbaiki model bisnis yang selama ini dijalankan.

Tujuan penelitian yang dilakukan ini adalah:

1. Mengidentifikasi model bisnis yang selama ini dilakukan oleh KNM Fish Farm dengan menggunakan Business Model Canvas (BMC), dan

2. Menciptakan model bisnis perbaikan bagi KNM Fish Farm.

\section{METODOLOGI}

Kerangka pikir dari penelitian ini dapat dilihat pada gambar 1 .

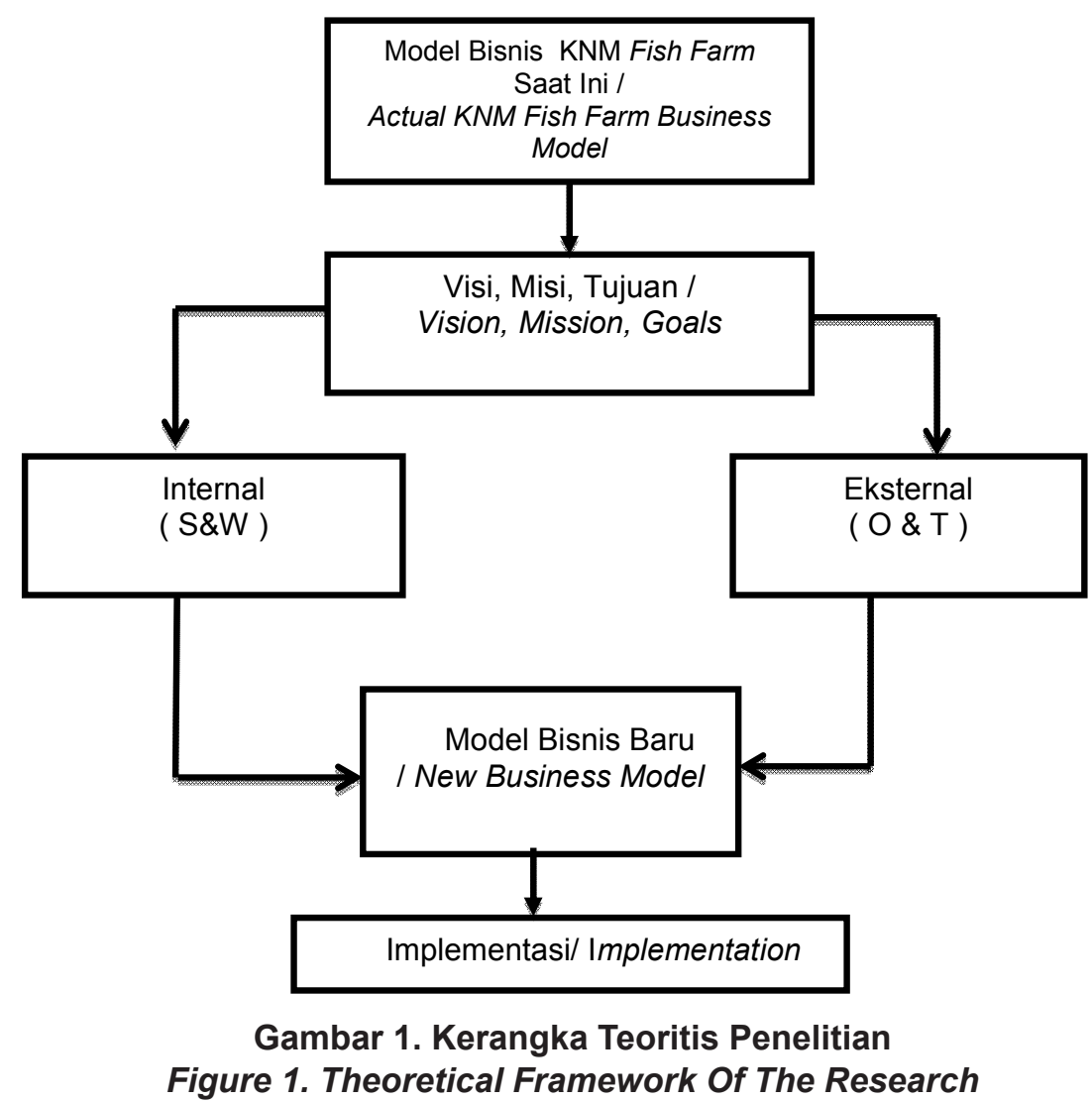


Metode yang digunakan adalah analisis deskriftif, yaitu menjawab permasalahan yang sedang dihadapi perusahaan dalam bentuk studi kasus sehingga didapatkan gambaran yang luas dan mendalam selama periode tertentu selama penelitian ini dilakukan. Penelitian ini menggunakan dua jenis data, yaitu data primer dan data sekunder. Instrumen untuk pengumpulan data primer diperoleh dari observasi langsung ke lapangan, wawancara dan pengisian kuisioner. Analisis data yang digunakan yaitu :

1. Analisis bisnis model, yaitu menggambarkan kondisi bisnis model yang selama ini digunakan oleh KNM Fish Farm dengan menggunakan pendekatan Business Model Canvas (BMC), yaitu sebuah konsep model bisnis yang dikembangkan oleh Osterwalder dan Pigneur yang berhasil mengubah konsep model bisnis yang rumit menjadi sederhana dan dapat dijadikan alternatif strategi perusahaan yang berujung pada kelayakan usaha (Dewobroto, 2013). Bisnis model juga dapat digunakan untuk menyusun formulasi strategi bisnis (Priandita \& Toha, 2013). BMC ditampilkan dalam bentuk kanvas yang berisikan 9 (sembilan) elemen yang terdiri dari customer segment, value proposition, channel, customer relationship, revenue stream, key resources, key activity, key partnership, dan cost structure.

2. Analisis SWOT dari masing-masing elemen model bisnis digunakan untuk mengetahui peluang dan ancaman serta kekuatan dan kelemahan yang dimiliki perusahaan agar selanjutnya dapat dibuat langkah untuk mengakomodasi kondisi dari hasil analisis SWOT yang telah dilakukan berupa strategi-strategi untuk perusahaan. Analisis SWOT dapat dilakukan dengan informasi yang didapat dari hasil analisis eksternal (peluang dan ancaman), analisis internal (kekuatan dan kelemahan), dan pengkajian terhadap nilai-nilai manajerial. Informasi yang diperoleh digunakan untuk menganalisis situasi yang dihadapi oleh perusahaan secara menyeluruh dan merumuskan langkah-langkah yang dapat diambil untuk mengantisipasi kemungkinankemungkinan yang akan terjadi.

3. Merancang model bisnis perbaikan, yang merupakan perbaikan dan penyempurnaan dari bisnis model yang lama. Penelitian ini dilakukan di KNM Fish Farm yang berlokasi di Kecamatan Cisaat Kabupaten Sukabumi pada bulan Desember 2013 - Februari 2014.

\section{HASIL DAN PEMBAHASAN}

\section{Identifikasi Elemen - Elemen Model Bisnis pada KNM Fish Farm}

Menurut Freund (2009) bahwa sebuah perusahaan yang ingin memperbaiki keberlanjutan usahanya harus mengubah model bisnisnya, baik secara radikal maupun inkremental dan merupakan sebuah usaha yang memerlukan pondasi normatif dan strategis yang harus bisa dipraktekkan melalui konsep-konsep dan instrumen yang memadai.

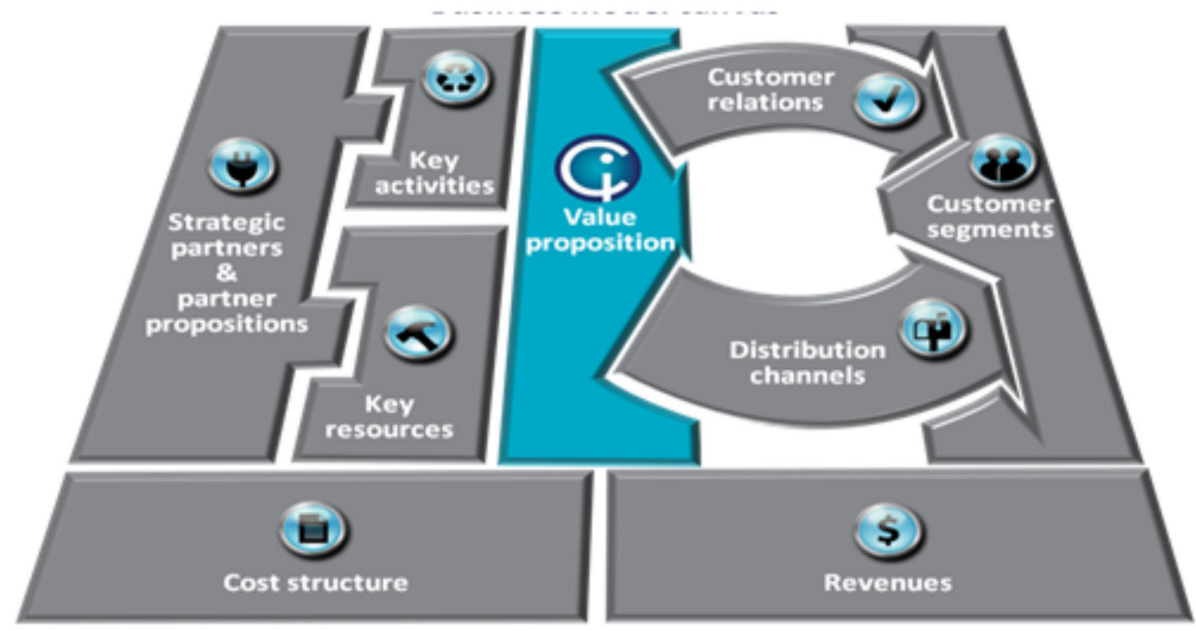

Gambar 2. Kanvas Model Bisnis

Figure 2. Business Model Canvas 
Pendekatan model bisnis merupakan salah satu faktor kritis untuk sukses dari suatu organisasi. Pendekatan model bisnis harus inovatif agar organisasi ma mpu bertahan ditengah cepatnya perubahan lingkungan bisnis.

Salah satu alat bantu pendekatan yang dapat digunakan adalah Business Model Canvas (BMC) yang dikembangkan oleh Osterwalder dan Pigneur (2012) yang memungkinkan untuk mendeskripsikan dan memanipulasi model bisnis dengan mudah dan sederhana untuk kemudian menciptakan alternatif strategi berupa model bisnis baru yang lebih kompetitif. Model bisnis akan membantu memahami, menjelaskan dan memprediksi aktivitas apa saja yang sebaiknya dilakukan agar menghasilkan keuntungan bagi perusahaan atau organisasi. Model bisnis merupakan suatu representasi abstrak bagaimana perusahaan menghasilkan uang, apa yang dapat ditawarkan perusahaan kepada konsumen, kepada siapa perusahaan akan menawarkan produknya dan bagaimana cara melakukannya.

Tahapan pertama dari penelitian ini adalah menganalisis model bisnis yang selama ini dijalankan oleh KNM Fish Farm, dan kemudian memetakannya pada Business Model Canvas (BMC) yang dapat dilihat pada Gambar 3.

\begin{tabular}{|c|c|c|c|c|}
\hline $\begin{array}{c}\text { Key } \\
\text { Partner }\end{array}$ & Key Activities & Value Proposition & $\begin{array}{l}\text { Customer } \\
\text { Relationship }\end{array}$ & Customer Segment \\
\hline $\begin{array}{l}\text { Penjual } \\
\text { ikan asin / } \\
\text { Salted fish } \\
\text { seller }\end{array}$ & $\begin{array}{l}\text { Pembenihan dan } \\
\text { budidaya ikan / } \\
\text { Hatcheries and fish } \\
\text { farming }\end{array}$ & $\begin{array}{l}\text { Produk ikan segar } \\
\text { tanpa bau lumpur / } \\
\text { Fresh fish products } \\
\text { without the smell of } \\
\text { mud }\end{array}$ & $\begin{array}{l}\text { Bantuan } \\
\text { personal khusus } \\
\text { / Special } \\
\text { personal } \\
\text { assistance }\end{array}$ & $\begin{array}{l}\text { Pedagang Pengumpul/ } \\
\text { tengkulak / Traders }\end{array}$ \\
\hline $\begin{array}{l}\text { Penjual } \\
\text { dedak / } \\
\text { Bran seller }\end{array}$ & $\begin{array}{l}\text { Pembuatan pakan ikan } \\
\text { / Manufacture of fish feed }\end{array}$ & $\begin{array}{l}\text { Praktis } \\
\text { / Practical }\end{array}$ & $\begin{array}{l}\text { Swalayan } \\
\text { / Self-service }\end{array}$ & $\begin{array}{l}\text { Pembeli perorangan, } \\
\text { tetangga, pelanggan } \\
\text { toko kelontong / }\end{array}$ \\
\hline $\begin{array}{l}\text { Peternak } \\
\text { ayam / } \\
\text { Chicken } \\
\text { farmer }\end{array}$ & & $\begin{array}{l}\text { Harga lebih murah } \\
\text { dibandingkan di } \\
\text { pasar tradisional } \\
\text { / Prices are cheaper } \\
\text { than in traditional } \\
\text { markets }\end{array}$ & & $\begin{array}{l}\text { Individual buyer, } \\
\text { neighbors, grocery store } \\
\text { customers }\end{array}$ \\
\hline Distributor & Key Resources & $\begin{array}{l}\text { Lokasi strategis } \\
\text { / Strategic location }\end{array}$ & Channel & \\
\hline sembako & $\begin{array}{l}\text { Areal perkolaman, sawah } \\
\text { / Pond areas, paddy } \\
\text { fields }\end{array}$ & $\begin{array}{l}\text { Jarak lebih dekat } \\
\text { daripada ke pasar ikan } \\
\text { atau pasar tradisional }\end{array}$ & $\begin{array}{l}\text { Langsung } \\
\text { melihat produk } \\
\text { / Immediately }\end{array}$ & \\
\hline $\begin{array}{l}\text { I Grocery } \\
\text { distributor }\end{array}$ & $\begin{array}{l}\text { Toko / } \\
\text { Store }\end{array}$ & $\begin{array}{l}\text { I The distance closer } \\
\text { than to the fish market } \\
\text { or traditional markets }\end{array}$ & see products & \\
\hline & $\begin{array}{l}\text { SDM / } \\
\text { Human Resources }\end{array}$ & & $\begin{array}{l}\text { Promosi dari } \\
\text { mulut ke mulut } \\
\text { / Mouth } \\
\text { to mouth } \\
\text { promotion }\end{array}$ & \\
\hline & & & \multicolumn{2}{|c|}{ Revenue Stream } \\
\hline \multicolumn{3}{|c|}{$\begin{array}{l}\text { Gaji karyawan / Employee salaries } \\
\text { Pembayaran PBB / Land and building tax payment }\end{array}$} & \multicolumn{2}{|c|}{$\begin{array}{l}\text { Penjualan produk ikan konsumsi dan hias / } \\
\text { Sales of consumer products and ornamental } \\
\text { fish }\end{array}$} \\
\hline \multicolumn{3}{|c|}{$\begin{array}{l}\text { Pembelian bahan baku pembuatan pakan dan pupuk / } \\
\text { Purchase of raw material for feed and fertilizer }\end{array}$} & \multicolumn{2}{|c|}{ Penjualan sembako/ Groceries selling } \\
\hline \multicolumn{5}{|c|}{$\begin{array}{l}\text { Pembelian peralatan budidaya ikan / Fish farming equipment } \\
\text { purchases }\end{array}$} \\
\hline
\end{tabular}


Identifikasi model bisnis menunjukkan bagaimana KNM Fish Farm dikelola dari generasi pertama sampai kedua yang telah berjalan sejak tahun 1953. Dimulai dari nilai/keunggulan yang ditawarkan (value proposition) berupa produk ikan segar tanpa bau lumpur dengan harga yang lebih murah dibandingkan harga di pasar tradisional dan lokasi yang strategis. Sasaran pasarnya (Customer segment)adalah pedagang tengkulak dan ibu rumah tangga dan tetangga. Hubungan dengan pelanggan (customer relationship) digunakan untuk menyampaikan nilai/keunggulan yang ditawarkan kepada konsumen, dibangun secara personal dan pelanggan melayani dirinya sendiri (self service). Kegiatan kunci (key activities) yang dilakukan berupa pembenihan dan pembuatan pakan ikan dan membutuhkan mitra kunci (key partner)seperti yang terlihat di Gambar 3. Kegiatan-kegiatan tersebut membutuhkan biaya (cost structure) dan akan menghasilkan pemasukan (revenue stream).

Menurut Rappa (2000) model bisnis merupakan metode yang digunakan perusahaan untuk menghasilkan uang di lingkungan bisnisnya, yang membuat perusahaan dapat bertahan. Menurut Wheelen dan Hunger (2010) juga mengungkapkan hal yang serupa yaitu model bisnis adalah suatu metode yang digunakan perusahaan untuk menghasilkan uang di mana perusahaan beroperasi.

\section{Analisis SWOT Elemen-Elemen Model Bisnis KNM Fish Farm}

Setelah mengidentifikasi elemen kanvas model bisnis yang selama ini dilakukan oleh KNM Fish Farm , maka tahap selanjutnya adalah melakukan analisis SWOT pada setiap elemen kanvas model bisnis. Menurut Rangkuti (2011), SWOT adalah suatu cara untuk mengidentifikasi berbagai faktor secara sistematis untukmerumuskan strategi perusahaan. Analisis ini mengacu pada pemikiran bagaimana memaksimalkan kekuatan (strengths) dan peluang (opportunities) serta secara bersamaan dapat meminimalkan kelemahan (weakness) dan ancaman (threats).

Analisis SWOT memberikan empat perspektif untuk menilai elemen-elemen suatu model bisnis, sedangkan Kanvas Model Bisnis memberikan fokus yang diperlukan untuk sebuah diskusi yang terstruktur. Kombinasi antara Kanvas Model Bisnis dengan SWOT memungkinkan penilaian yang terfokus dan evaluasi terhadap model bisnis organisasi dan blok bangunannya. Analisis seperti ini memberikan dasar baik untuk diskusi lebih lanjut, pengambilan keputusan dan akhirnya inovasi di sekitar model bisnis (Osterwalder \& Pigneur, 2012).

Hasil analisis SWOT diperoleh faktor internal berupa kekuatan terbesar ada pada elemen key resources, dan kelemahan pada key activities dan value propotitions, sedangkan faktor eksternal berupa peluang pada elemen customer segments dan ancaman pada elemen revenue stream.

\section{Perbaikan Business Model Canvas (BMC) KNM Fish Farm}

Tahap selanjutnya yaitu merancang perbaikan bisnis model KNM Fish Farm di masa yang akan datang. Pada tahap ini penulis berpedoman pada hasil Focus Grup Discussion (FGD) yang telah dilakukan dengan pemilik usaha dan para generasi ketiga, dengan mempertimbangkan visi perusahaan, yaitu terwujudnya perusahaan keluarga yang bergerak di bidang perikanan yang terintegrasi, mandiri, inovatif, berwawasan lingkungan, berdaya saing dan berkelanjutan, serta hasil dari analisis SWOT, sehingga menghasilkan model bisnis perbaikan seperti pada Gambar 4 . Perbaikan yang dilakukan untuk masing-masing elemen Business Model Canvas (BMC) adalah sebagai berikut:

\section{Value Proposition (keunggulan yang ditawarkan):}

Menjelaskan mengenai penawaran produk dan jasa/layanan yang mempunyai keunggulan/ nilai lebih (value) yang akan diberikan kepada segmen konsumen baik bersifat kuantitatif (harga dan efisiensi) maupun kualitatif (pengalaman konsumen). Keunggulan/nilai lebih (value) yang ditawarkan dapat berupa produk baru, mutu produk/ jasa yang lebih baik, desain yang unik, status atau brand, harga yang lebih murah/kompetitif, kemudahan akses dan lain-lain (Osterwalder \& Pigneur, 2012).

Beberapa Value Proposition baru yang bisa ditawarkan kepada pelanggan yang lebih luas antara lain :

1. One stop services untuk seluruh anggota keluarga meliputi pemenuhan kebutuhan pokok, rekreasi dan edukasi. Pada model bisnis sebelumnya toko sembako dan penjualan ikan dilakukan di lokasi yang berbeda. Pada model bisnis perbaikan kedua jenis kegiatan tersebut digabungkan 
dan ditambah dengan produk lainnya yaitu olahan ikan, terapi ikan dan pemancingan, sehingga konsumen beserta seluruh anggota keluarga dapat melakukan aktivitas di satu lokasi.

2. Variasi produk olahan ikan yang beragam, dan dikemas secara menarik. Kecenderungan masyarakat yang enggan mengkonsumsi ikan, terutama anak-anak salah satunya karena bau amis yang masih tercium bila dikonsumsi dalam bentuk utuh. Bagi ibu rumah tangga dan wanita bekerja yang tidak memiliki cukup banyak waktu karena cara pengolahan ikan yang lebih sulit dibandingkan daging sapi dan ayam. Produk-produk olahan ikan yang bisa ditawarkan kepada konsumen antara lain ikan goreng, pepes, nugget, bakso, bakso tahu, dendeng, ikan asin, dll.

\begin{tabular}{l} 
Key Partner \\
\hline Konsultan pengolahan \\
dan pemasaran produk \\
perikanan (KKP, Kemenkop \\
UKM, Dinkes, pelaku usaha) \\
/ Consultant processing \\
and marketing of fisheries \\
products (MMAF, Ministry of \\
Cooperative SMEs, health \\
offices, business actors)
\end{tabular}

Konsultan integrated fish farming/ Integrated fish farming Consultant

SMK Pertanian, Perikanan, Akuntansi, Tata Boga(SDM)/ Vocational Agriculture, Fisheries, Accounting, Hospitality Catering (HR)

Distributor bahan kebutuhan pokok (sembako)/ Distributor of basic necessities (groceries)
1. Produksi bahan baku dengan penerapan integrated fish farming(hulu)

1. Production of raw materials with the application of integrated fish farming (upstream)

2. Litbang teknologi dan SDM 2. $R \& D$ technology and $H R$

3. Pengolahan dan pemasaran produk (hilir)

3. The processing and marketing of products (downstream)

4. Aliansi mitra

4. Partners Alliance

\section{Key Resources}

Bangunan toko,

pasar ikan mini, kolam,

lahan budidaya / Store

Building , mini fish market,

ponds, land cultivation
SDM dan finansial/ HR and financial

Value Proposition
1. one stop services
untuk seluruh
anggota keluarga
meliputi pemenuhan
kebutuhan pokok,
rekreasi dan
edukasi/ One stop
services for the
entire family includes
subsistence,
recreational and
educational
2. Variasi produk
olahan ikan
yang beragam,
siap makan dan
dikemas menarik
2. The variation
of processed
fish products are
diverse, ready meals
and interesting
packaged

\begin{tabular}{ll}
\multicolumn{1}{c}{$\begin{array}{c}\text { Customer } \\
\text { Relationship }\end{array}$} & \multicolumn{1}{c}{$\begin{array}{c}\text { Customer } \\
\text { Segment }\end{array}$} \\
$\begin{array}{l}\text { Bantuan } \\
\text { personal khusus } \\
\text { / Personal } \\
\text { assistance }\end{array}$ & $\begin{array}{l}\text { 1.Ibu rumah } \\
\text { tangga dan } \\
\text { wanita bekerja / } \\
\text { Housewives and } \\
\text { working women }\end{array}$ \\
Swalayan / Self & $\begin{array}{l}\text { 2. Penyelenggara } \\
\text { pesta / Party } \\
\text { service }\end{array}$ \\
& $\begin{array}{l}\text { organizers } \\
\text { 3. Pelaju / } \\
\text { Commuters } \\
\text { Communities }\end{array}$ \\
& $\begin{array}{l}\text { 4. Wisatawan / } \\
\text { Traveler }\end{array}$
\end{tabular}

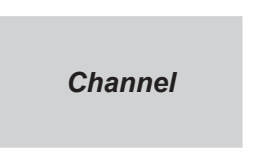

5. Anak Sekolah/ School students

Minimarket,

pasar ikan mini /

Minimarket, mini

fish market

6. Instansi Pemerintah dan swasta /

Kolam

terapi dan

pemancingan

I Therapy dan

fishing ponds

Jejaring Media

Sosial, web,

blog, spanduk,

brosur

Social media,

web, blog,

banner,

brochure institution and the private sector

\begin{tabular}{ll}
\hline & \multicolumn{1}{c}{ Revenue Stream } \\
\hline $\begin{array}{l}\text { Gaji karyawan, pembayaran PBB / } \\
\text { Employee salaries, land and building tax payment }\end{array}$ & $\begin{array}{l}\text { Penjualan ikan konsumsi dan hias/ } \\
\text { Consumption andornamental fish } \\
\text { sales }\end{array}$ \\
$\begin{array}{ll}\text { Pembelian peralatan budidaya ikan dan pertanian dan peternakan / } \\
\text { Purchase of fish farming and agricultural and livestock equipment }\end{array}$ & penjualan sembako / Groceries \\
& selling \\
& Penjualan produk olahan ikan / Sales \\
Pembelian peralatan pengolahan ikan / Fish processing equipment purchases & Jasa pemancingan / Fishing services \\
Pembangunan minimarket, kolam pemancingan dan terapi / & Jasa terapi ikan/ \\
Development minimarket, fishing pond and therapy & Fish therapy services \\
\hline
\end{tabular}

\section{Gambar 4. Perbaikan Business Model Canvas KNM Fish Farm}

Figure 4. Business Model Canvas Revision of KNM Fish Farm 


\section{Customer Segments (target pelanggan utama):}

Menurut Osterwalder \& Pigneur (2012), pelanggan merupakan inti dari semua model bisnis. Untuk dapat memuaskan pelanggan, perusahaan dapat mengelompokkan pelanggannya dalam segmen-segmen yang berbeda berdasarkan kesamaan kebutuhan, perilaku, dan atribut lain. Suatu organisasi harus memutuskan segmen mana yang dilayani dan mana yang diabaikan. Setelah itu, barulah organisasi dapat merancang model bisnis dengan pemahaman yang tepat mengenai kebutuhan spesifik pelanggan.

Lokasi usaha berada di tempat yang strategis yaitu berada di pinggir jalan raya dan di kawasan niaga, perkantoran, sekolah mulai dari PAUD sampai perguruan tinggi dan pemukiman, oleh karena itu terdapat berbagai segmen pasar baru yang telah diidentifikasi, yaitu. :

1. Ibu Rumah Tangga dan wanita pekerja. Di sekitar lokasi usaha juga terdapat pemukiman, perkantoran instansi pemerintah maupun swasta, sehingga banyak terdapat ibu rumah tangga dan wanita pekerja yang sudah tidak banyak memiliki waktu untuk ke pasar dan memasak. Segmen pasar ini juga ditawarkan ikan olahan dan kebutuhan pokok (sembako).

2. Penyelenggara pesta. Salah satu ikan olahan yang akan diproduksi yaitu pepes ikan mas yang merupakan salah satu makanan khas yang biasanya disajikan di dalam jamuan pesta/selamatan di daerah Jawa Barat. Selain itu di dalam acara pesta juga sering disajikan jajanan olahan ikan seperti empek-empek, bakso tahu, bakso ikan, dll. Ini membuka peluang untuk menawarkan olahan ikan.

3. Pelaju. Lokasi usaha yang berada di pinggir jalan raya, membuka peluang untuk membidik segmen pasar pelaju, yaitu orang yang bepergian ke luar kota seperti Bogor, Jakarta, Cianjur atau Bandung dengan tujuan bekerja, kuliah atau mengunjungi keluarga. Mereka merupakan segmen pasar bagi produk ikan olahan yang akan mereka bawa sebagai bekal atau oleh-oleh.

4. Wisatawan. Sukabumi memiliki objek wisata alam seperti Situ Gunung dan Selabintana. Jumlah wisatawan diperkirakan akan terus bertambah dengan dibukanya jalur kereta api ke Bogor dan Cianjur dan rencana pembangunan jalan tol Bogor Ciawi Sukabumi
(Bocimi) di masa mendatang. Segmen pasar ini dapat dibidik untuk toko oleh-oleh khas kecamatan Cisaat berupa produk olahan ikan.

5. Anak sekolah. Segmen pasar ini dibidik untuk produk olahan ikan, ikan hias, terapi ikan dan pemancingan.

6. Instansi pemerintah dan swasta. Segmen pasar ini dibidik untuk produk pelatihan perikanan, pemancingan, pasar ikan mini yang menyediakan olahan ikan.

\section{Channels (media yang digunakan untuk menjangkau customer segment):}

Alat atau media yang digunakan perusahaan/ organisasi berkomunikasi atau mencapai target konsumennya, sehingga keunggulan/nilai lebih (value) perusahaan/organisasi dapat diterima oleh target konsumen. Perusahaan dan pelanggan dihubungkan melalui saluran komunikasi, distribusi dan penjualan. Saluran memiliki beberapa fase yang berbeda, yaitu:

1. Meningkatkan kesadaran pelanggan serta evaluasi terhadap produk dan jasa yang ditawarkan oleh perusahaan. Media yang digunakan adalah jejaring media sosial, pesan singkat, web, blog, dan digital printing seperti spanduk dan brosur.

2. Tempat penjualan dan pemberian pelayanan jasa yang terdiri dari minimarket, pasar ikan mini, kolam terapi dan pemancingan.

\section{Customer Relationships (Cara menjaga hubungan baik dengan customer):}

Menggambarkan berbagai jenis hubungan perusahaan yang ingin dibangun bersama segmen pelanggan yang dilakukan karena didorong motivasi untuk mengakuisisi pelanggan, mempertahankan pelanggan atau meningkatkan penjualan. Perbaikan dilakukan melalui bantuan personal khusus, dengan petugas pelayanan yang khusus diperuntukkan bagi klien individu yang bersifat jangka panjang dan diberikan kepada pelanggan pesan antar, terutama untuk produk olahan ikan. Swalayan, perusahaan menyediakan semua sarana sehingga pelanggan dapat membantu dirinya sendiri, seperti pada minimarket. Bentuk yang ketiga dengan memanfaatkan komunitas pengguna yang memungkinkan bertukar pengetahuan dan saling membantu dalam memecahkan masalah, seperti komunitas pecinta ikan, terapi ikan dan pemancing. 


\section{Revenue Streams (Arus pendapatan):}

Blok ini menggambarkan uang tunai yang dihasilkan perusahaan dari masing-masing segmen pelanggan. Penjualan ikan konsumsi dan hias yang pada awalnya dijual ke tengkulak, di masa depan akan dilakukan sendiri di pasar ikan mini yang berintegrasi dengan minimarket yang menjual bahan kebutuhan pokok (sembako) dan olahan ikan. Aliran pendapatan juga akan dihasilkan dari kolam terapi ikan dan pemancingan.

\section{Key Activities (kegiatan operasional utama yang dilakukan)}

Merupakan tindakan-tindakan penting yang harus diambil perusahaan agar dapat beroperasi dengan sukses. Aktivitas-aktivitas kunci dibutuhkan untuk menciptakan dan memberikan proposisi nilai, menjangkau pasar, mempertahankan hubungan baik dengan pelanggan dan pada akhirnya dapat menghasilkan pendapatan.

Perbaikan yang dilakukan berupa:

1. Penerapan integrated fish farming, yaitu memadukan kegiatan perikanan dengan pertanian dan peternakan yang berfungsi sebagai penyedia bahan baku pengolahan ikan, bahan baku pakan ikan dan penyedia sumber energi. Kegiatan perikanan membutuhkan pakan ikan yang dapat diperoleh dari kegiatan pertanian seperti talas, jagung dan singkong serta peternakan berupa budidaya bekicot dan cacing tanah. Kegiatan pertanian yang memanfaatkan pematang kolam, dapat menghasilkan bahan baku berupa bumbu masakan seperti kunyit, jahe, cabe, serai, tomat, dll. Limbah dari kegiatan pengolahan ikan dapat dijadikan bahan baku pembuatan biogas yang dapat digunakan sebagai sumber energi bagi proses pengolahan ikan. Selain itu, pupuk cair dan padat yang dihasilkan dari proses biogas dapat digunakan untuk pemupukan kolam dan tanaman pertanian.

2. Penelitian dan pengembangan teknologi dan SDM Diperlukan berbagai penelitian dan pengembangan baik yang berhubungan dengan teknologi yang bisa diaplikasikan dalam berbagai kegiatan yang akan dilakukan maupun dalam pengelolaan dan pengembangan SDM.

3. Pengolahan dan pemasaran produk olahan ikan. Berbagai kegiatan kunci perlu dilakukan untuk mengolah bahan baku menjadi produk akhir yang akan ditawarkan kepada segmen pasar yang dituju. Pemasaran produk dilakukan dengan berbagai media pendukung yang telah dipilih dalam channel.

4. Aliansi mitra. Berbagai bentuk kerjasama untuk mengakuisisi berbagai kompetensi dan memperoleh sumber daya utama dengan berbagai pihak pada key partnerships

\section{Key Resources (Sumber Daya utama yang dimiliki) :}

Menggambarkan aset-aset terpenting yang diperlukan agar sebuah model bisnis dapat berfungsi. Sumber daya utama dapat berbentuk :

1. Fisik, yaitu bangunan toko/minimarket, pasar ikan mini, kolam terapi dan pemancingan, dan lahan budidaya.

2. Finansial, diperlukan sebagai dana bagi pembangunan sarana fisik maupun operasional yang diperoleh dari simpanan pemilik usaha.

3. Manusia, merupakan aset yang paling penting karena model bisnis ini memerlukan inovasi dan perlu kreativitas dalam pengembangan produk-produk yang akan dihasilkan. Memberdayakan para generasi ke-3 dengan berbagai kemampuan dan kapabilitas yang dimilikinya serta merekrut tenaga-tenaga handal terdidik.

\section{Key Partnerships (mitra kerja utama):}

Menggambarkan hubungan dengan pihak ketiga/merupakan partner/mitra utama yang penting agar model bisnis dapat berjalan lancar. Tujuan bermitra adalah untuk mengoptimalkan model bisnis diantaranya: Mendapatkan harga murah karena skala ekonomis, mengurangi risiko (reinsurance) dan menambah sumber daya, memperoleh sumberdaya yang lebih unggul dan atau yang tidak dimiliki mitra kerja utama yang perlu dimiliki :

1. Konsultan dalam hal integrated fish farming dan pengolahan serta pemasaran produk perikanan dari Kementerian Kelautan dan Perikanan (KKP), Kementerian Koperasi dan UKM, serta Dinas Kesehatan, yang membantu ijin Pangan Industri Rumah Tangga (P-IRT), para penyuluh serta para pelaku usaha yang telah lebih dahulu berhasil mengembangkan usahanya dapat dijadikan 
mitra dan sumber informasi.

2. Penyedia SDM handal yang bisa dijadikan sebagai karyawan yaitu : SMK Perikanan, Akuntansi, dan tata Boga.

3. Distributor produk kebutuhan pokok sebagai mitra bagi toko sembako/minimarket.

\section{Cost Structure (struktur biaya)}

Menggambarkan semua biaya yang dikeluarkan untuk mengoperasikan model bisnis, yaitu :

1. Pembangunan fasilitas fisik minimarket, pasar ikan mini, kolam terapi dan pemancingan.

2. Pembelian peralatan budidaya, pengolahan dan pengemasan ikan.

3. Gaji karyawan, pajak, perijinan dan biaya promosi.

\section{KESIMPULAN DAN IMPLIKASI KEBIJAKAN}

\section{Kesimpulan}

Model bisnis membantu memahami, menjelaskan dan memprediksi aktivitas apa yang sebaiknya dilakukan untuk dapat menghasilkan keuntungan bagi perusahaan atau organisasi. Model bisnis juga merupakan representasi abstrak bagaimana perusahaan menghasilkan uang. Business Model Canvas (BMC) memiliki sembilan elemen yang penting dalam membantu mengidentifikasikan model bisnis yang selama ini dijalankan oleh KNM Fish Farm, dan membantu untuk mengidentifikasi elemen - elemen yang memerlukan perbaikan untuk membantu keberlangsungan usaha di masa depan. Hasil yang diperoleh bahwa KNM Fish Farm perlu untuk melakukan perbaikan pada semua elemen BMC, yaitu: (1) customer segmentations: dari pedagang tengkulak diperluas pada ibu rumah tangga, wanita bekerja, penyelengga pesta, pelaju, wisatawan, anak sekolah serta instansi pemerintah dan swasta (2) value proposition: one stop services dan variasi produk olahan ikan yang beragam (3) customer relationship: ditambah dengan komunitas (4) channels: tempat penjualan berupa minimarket, pasar ikan mini, kolam terapi dan pemancingan. Sarana promosi berupa jejaring sosial, web, blog, spanduk dan brosur, (5) revenue streams: ditambah penjualan produk olahan ikan, terapi ikan dan pemancingan, (6) key resources: toko, pasar ikan mini, kolam, lahan budidaya, SDM dan finansial, (7) key activities: produksi bahan baku melalui integrated fish farming, litbang teknologi dan SDM, Pengolahan dan pemasaran produk serta aliansi mitra, (8) key partnerships: konsultan pengolahan dan pemasaran ikan, integrated fish farming, SMK dan distributor sembako (9) cost structure:pembangunan sarana fisik, pembelian peralatan budidaya dan pengolahan ikan, gaji karyawan, pajak, perijinan dan biaya promosi.

\section{Implikasi Kebijakan}

Hasil penelitian ini merupakan rekomendasi perbaikan model bisnis yang berimplikasi pada Rekomendasi kebijakan yang dapat dilakukan oleh KNM Fish Farm maupun pemerintah adalah sebagai berikut:

1. KNM Fish Farm perlu mempersiapkan secara detail dan komprehensif kajian mengenai pendanaan, desain bangunan, kapabilitas SDM serta faktor teknologi tepat guna yang akan digunakan dalam bentuk business plan. Hal yang perlu mendapat perhatian diantaranya kajian mengenai jenis produk yang akan dikembangkan, riset pasar dan kecenderungan konsumen terhadap suatu produk yang akan dihasilkan.

2. Pada elemen key activities, diidentifikasi kegiatan integrated fish farming yang merupakan salah satu aplikasi blue economy, dengan memanfaatkan output dari suatu kegiatan baik berupa produk utama maupun sampingan (limbah) untuk menjadi input bagi kegiatan lainnya sehingga dapat menggunakan sumberdaya yang dimiliki secara lebih efisien, menghasilkan produk dan nilai ekonomi yang lebih besar.

3. Pada elemen key partner teridentifikasi kebutuhan akan peran serta pemerintah melalui instansi terkait seperti Kementerian Kelautan dan Perikanan, Kementerian Koperasi dan UKM, Dinas Kesehatan dan lain-lain. Bantuan yang selama ini biasa diberikanoleh pemerintah kepada para pelaku usaha dalam bentuk dana, peralatan maupun pelatihan namun terkadang tidak tepat sasaran. Pendampingan dari penyuluh masih sangat kurang dirasakan oleh para pelaku usaha, baik dalam hal jumlah maupun perannya dalam memajukan usaha para pelaku usaha di bidang perikanan.

4. Materi pelatihan yang diberikan tidak hanya bersifat teknis, tetapi juga manajerial 
sehingga para pelaku usaha perikanan dapat mendayagunakan kekuatan sendiri yang dimiliki dan tidak mengantungkan bantuan dana dari pemerintah.

\section{DAFTAR PUSTAKA}

Dewobroto, S. 2013. Penggunaan Business Model Canvas sebagai Dasar untuk Menciptakan Alternatif Strategi Bisnis dan Kelayakan Usaha. Jurnal Teknik Industri Universitas Trisakti, 215-230.

Freund, F.L. 2009. Business Model Concepts in Corporate Sustainability Contexts. Lueneburg : Leuphana University of Lueneburg.

Osterwalder, A. \& Y. Pigneur. 2012. Business Model Generation. PT Elex Media Komputindo. Jakarta. Hal $14-216$.
Priandita, A. \& M. Toha. 2013. Business Strategy Formulation Using Business Model Case Study: PT Kartina Tri Satria. The Indonesian Journal of Business Administration. 2 (1):68-75.

Rangkuti, F. 2011. SWOT Balance Scorecard. PT. Gramedia Pustaka Utama. Jakarta. Hal $195-200$.

Rappa, M. 2002. Business Models on The Web. (ONLINE). http://digital enterprise.org/ models.html. [15 Juni 2013]

Sa'id, E. G. 2010. Wawasan, Tantangan dan Peluang Agrotechnopreneur Indonesia. IPB Press. Bogor. Hal. 7-8.

Wheelen, T. L. \& J. D. Hunger. 2010. Strategic Management and Business Policy: Achieving Sustainability. New Jersey: Prentice Hall 